\title{
Concepções do profissional farmacêutico sobre a assistência farmacêutica na unidade básica de saúde: dificuldades e elementos para a mudança
}

\author{
Aílson da Luz André de Araújo ${ }^{1,2}$, Osvaldo de Freitas ${ }^{2 *}$ \\ ${ }^{1}$ Faculdades Federais Integradas de Diamantina, ${ }^{2}$ Departamento de Ciências Farmacêuticas, Faculdade de Ciências \\ Farmacêuticas de Ribeirão Preto, Universidade de São Paulo
}

*Correspondência:

O. de Freitas

Departamento de Ciências

Farmacêuticas

Faculdade de Ciências Farmacêuticas

de Ribeirão Preto - USP

Av do Café, s/n

14040-903 - Ribeirão Preto, SP - Brasil

E-mail: ofreitas@fcfrp.usp.br

\begin{abstract}
No presente estudo foi feita avaliação da Assistência Farmacêutica em farmácias de Unidades de Saúde do município de Ribeirão Preto, no Estado de São Paulo, Brasil. Partindo-se do referencial de avaliação tecnológica em saúde e suas interfaces, foram realizadas entrevistas com os profissionais farmacêuticos, procurando-se conhecer as concepções desses atores sobre a assistência farmacêutica. Os resultados obtidos mostram um trabalho baseado na gestão burocrática dos medicamentos com objeto no controle de estoque do medicamento. Alguns elementos emergentes que poderão contribuir para a alteração deste quadro foram detectados: voluntarismo, busca pela valorização profissional, iniciativa de integração com a equipe de saúde, percepção do paciente como objeto de trabalho e formação profissional complementar.
\end{abstract}

\author{
Unitermos \\ - Assistência farmacêutica \\ - Tecnologia \\ - Atenção farmacêutica
}

\section{INTRODUÇÃO}

Este estudo teve como referencial teórico uma concepção abrangente de tecnologia em saúde, ou seja, "constituida pelo saber e por seus desdobramentos materiais e não-materiais na produção dos serviços de saúde" (Gonçalves, 1994). Neste sentido, procurou-se fugir da mera redução do conceito aos aspectos relacionados aos instrumentos de trabalho e suas funções técnicas nos processos produtivos.

Os serviços de saúde podem ser organizados de diferentes formas, de acordo com o modelo tecnológico ou modalidade assistencial. São caracterizados conforme o grau de incorporação tecnológica em: atenção básica, nível secundário, nível terciário e outros. Quanto ao tipo de propriedade em: privado, estatal, filantrópico, previdenciário e outros. Conforme a natureza do serviço em: unidades que fazem saúde pública, atenção primária ou atendimento hospitalar (Campos, 1992).
Estas diversas modalidades estariam articuladas segundo uma lógica específica e dominante do modelo assistencial, ou forma de produção de serviços, ou conformação do sistema de saúde assim definida: "uma modalidade de intervenção do Estado, resultante dos diversos sentidos que adquirem as políticas de confronto de classes e de interesses, num determinado modo de produção de distribuição da atenção à saúde, em conjunturas especificas" (Carvalho, 1993). Ou, ainda, "um modo como são produzidas as ações de saúde e a maneira como serviços de saúde e o Estado se organizam para produzilas e distribuí-las" (Campos, 1979).

Esse modelo assistencial ao interagir com os diferentes modelos tecnológicos altera as características ideais (arquétipos) destes, determinando a sua lógica hegemônica: liberal, neoliberal, socialista e outros.

No Brasil, historicamente foram implementados diversos modelos tecnológicos na saúde pública. No Estado 
de São Paulo, particularmente, Gonçalves (1994) faz breve revisão do assunto, conforme o período histórico. Num primeiro momento, baseado numa Epidemiologia nascente, foi implementado o modelo do "campanhismo", com ênfase na utilização da política sanitária e das campanhas de vacinação e higienização. Esse modelo predominou até meados dos anos 20 do século passado, quando Geraldo $\mathrm{H}$. de Paula Souza reorganizou o Serviço Sanitário do Estado, privilegiando a Educação Sanitária como o principal instrumento de trabalho e o Centro de Saúde como apare1ho. Este modelo, também chamado de médico-sanitário, predominou até a década de 1960.

Nos anos 1960, através de reformas administrativas, foram delimitados os aspectos do modelo, caracterizado pela assistência médica individual como meio para a realização de objetivos epidemiológicos definidos. As bases desse modelo foram: integração de serviços, centralização normativa e sistemas de informação. Com participação cada vez mais crescente da medicina curativa, caracterizada pelo atendimento previdenciário, esse modelo pressupunha extensão crescente da cobertura dos serviços de assistência médica para a melhoria das condições de saúde. No nosso ponto de vista, este modelo ainda se faz presente com grande impacto no sistema de saúde, mesmo após a implantação do SUS.

Finalmente, no final da década de 1980, começou a tentativa de reverter o modelo vigente, com a definição do SUS e suas políticas de integralidade, igualdade de acesso e gestão democrática. Neste contexto histórico, temos a definiç̧ão legal da Assistência Farmacêutica e das Políticas de Medicamentos, que até então não faziam parte da pauta de discussão dos atores responsáveis pela definição das Políticas de Saúde. É neste momento que o farmacêutico começa a atuar mais efetivamente na saúde pública, procurando construir um espaço diferenciado para o medicamento no modelo assistencial, espaço esse que para nós ainda está para ser mais bem definido.

Nesta perspectiva, partimos do pressuposto de que o conhecimento sobre os medicamentos e seu desdobramento na prestação de um serviço de saúde, consubstanciada no Brasil no termo Assistência Farmacêutica, constitui, para nós, formas específicas de tecnologia, demandando conhecimentos específicos para sua operacionalização.

Nesta linha de abordagem, acreditamos, a princípio, que todas essas atividades relacionadas ao medicamento, norteadas pelo termo Assistência Farmacêutica, integram o modelo tecnológico específico do serviço em que estão inseridas, articulando-se a este e determinadas igualmente pela lógica do modo de produção hegemônico dos serviços de saúde.
Tendo como parâmetro o anteriormente exposto, em nosso estudo procuramos analisar os diferentes aspectos dessa tecnologia na prestação direta de serviços ao usuário, utilizando como modelo as farmácias da rede básica de saúde no município de Ribeirão Preto, na perspectiva de contribuir para a construção de teoria sistematizadora destas práticas no Sistema Único de Saúde (SUS).

Na primeira parte do estudo, preocupamo-nos em analisar as diferentes concepções dos profissionais envolvidos na assistência farmacêutica, contextualizado por algumas informações de cunho demográfico. Posteriormente, essas informações foram complementadas por observações do processo de atendimento.

\section{CASUÍSTICA E MÉTODOS}

População alvo: foi constituída pelos profissionais farmacêuticos envolvidos no trabalho das farmácias das unidades da rede básica de saúde de Ribeirão Preto.

Delineamento do estudo: o referencial teórico deste estudo é uso de tecnologias em saúde, consubstanciada em uma pesquisa qualitativa (Gonçalves, 1994; Minayo, 2000; Novaes, 2000).

A principal busca foi no sentido de apreender o mais fielmente possível a realidade da Assistência Farmacêutica no município escolhido, tendo como fonte privilegiada a fala daquele que consideramos o ator principal dessa atividade: o farmacêutico envolvido no trabalho da unidade de saúde. Entretanto, por se tratar de forma de abordagem ainda pouco utilizada nas Ciências Farmacêuticas, tornase necessária breve descrição do método utilizado na pesquisa.

A propósito da investigação social utilizando dados de entrevistas, a sociologia utiliza o conceito de representação social, que é definida como a reprodução de uma percepção anterior ou do conteúdo do pensamento (Minayo, 2000). Ou seja, é uma expressão da realidade, visando explicá-la, justificá-la ou questioná-la.

Essas representações têm a marca da realidade social onde nascem, mas possuem vida independente e reproduzem tendo com causa, outras representações e não apenas a estrutura social. Não existem representações falsas, pois todas respondem de diferentes formas a condições dadas à existência humana (Durkheim, apud Minayo, 2000).

As representações, no seu sentido de interpretação, relacionam-se com as interações de indivíduos e grupos, "não existe a possibilidade de alguém 'representar" livre da influência do seu conviver social”. Elas não são apenas cognição (imagens, conceitos, categorias, teorias), 
mas devem ser entendidas no seu contexto de produção material. Porém, tais representações não são dadas diretamente através da fala das pessoas, mas o seu significado é construído pela análise do discurso e do contexto social onde ele é produzido (Iturri, 1998).

Fonte dos Dados: entrevistas semi-estruturadas com os profissionais farmacêuticos que atuavam na rede básica de saúde do município de Ribeirão Preto - SP, no período de outubro de 2003 a agosto de 2004. A pesquisa foi previamente aprovada pelo comitê de ética da Faculdade de Ciências Farmacêuticas de Ribeirão Preto, USP (Processo n. 20 CEP/FCFRP) e contou com a anuência da Secretaria da Saúde de Ribeirão Preto (Of. 3221/02).

\section{Variáveis do Estudo}

Variáveis relativas às concepções dos farmacêuticos obtidas nas entrevistas;

Variáveis sócio-demográficas: sexo, escolaridade, instituição formadora, tempo de graduação, pós-graduação, atuação na rede básica.

Instrumentos para coleta dos dados: Os dados foram transcritos para o instrumento de coleta de dados validados na fase piloto de investigação (Anexo 1).

Análise dos Dados: Os dados foram analisados utilizando-se a análise de conteúdo e estatística descritiva.

\section{RESULTADOS E DISCUSSÃO}

\section{As unidades de saúde e as farmácias}

As unidades básicas de saúde constituem a principal porta de entrada para o sistema estatal de assistência à saúde em nosso país. Na época de realização deste estudo (outubro de 2003 a outubro de 2004), a rede básica de saúde no Município era constituída por cinco distritos sanitários, com 35 unidades de saúde, além de um ambulatório especializado em doenças sexualmente transmissíveis e três em saúde mental, sendo um vinculado à unidade distrital de saúde. Das 35 unidades, 33 possuíam farmácia e em somente 12 havia o profissional farmacêutico, pelo menos, em um dos períodos de funcionamento.

O serviço farmacêutico estava estruturado na Divisão de Farmácia e Apoio Diagnóstico, a qual era responsável pelo serviço no nível local das unidades de saúde e pelo planejamento, coordenação e assessoramento da execução da política de medicamentos do município.
As farmácias das unidades de saúde ocupavam, em geral, espaço relativamente pequeno, cerca de $20 \mathrm{~m}^{2}$, com pequenas variações conforme as dimensões da unidade de saúde. Estavam estruturadas como local de armazenamento e a dispensação dos medicamentos era feita por uma abertura na divisória que separava o ambiente da farmácia daquele destinado ao usuário. A predominância destas características foi independente de ser a estrutura da unidade antiga, nova ou reformada e se deve, provavelmente, ao fato de proporcionarem entrega rápida e quase impessoal do medicamento. Este fato também reflete o modelo ainda baseado na medicina curativa e com demanda crescente, no qual o serviço farmacêutico se restringe ao atendimento da demanda, porém dificulta a interação farmacêutico-usuário.

A jornada de trabalho dos farmacêuticos era de quatro horas diárias (20 horas semanais), porém, era freqüente a realização de dois turnos em unidades diferentes. As unidades com maior demanda (distritais) contavam com dois farmacêuticos, um em cada período, e as de menor (bairro) contavam com farmacêutico em apenas um período, apesar de a farmácia funcionar em período integral.

Os farmacêuticos pertencentes ao quadro de pessoal da Prefeitura de Ribeirão Preto predominaram na composição da amostra pesquisada, sendo a vinculação assim distribuída: Secretaria Municipal de Saúde (9); Universidade Privada (2); Universidade Pública (1); Secretaria Estadual de Saúde (1). Esta predominância é um fator positivo, no sentido da estruturação do serviço, sob o ponto de vista técnico-administrativo.

\section{Os farmacêuticos: aspectos gerais}

Foram entrevistados treze farmacêuticos, que atuavam em unidades da rede municipal de Saúde. Destes, dez eram do sexo feminino e três do masculino. A maioria deles, egressos da Universidade Pública, sendo oito da Universidade de São Paulo, campus de Ribeirão Preto; três da Universidade Estadual Paulista Júlio de Mesquita Filho, campus de Araraquara e dois da Universidade de Ribeirão Preto. A formação predominante foi de farmacêutico Industrial ou equivalente (08/13), cuja graduação ocorreu no período de 1991 a 1995 (07/13). Esta homogeneidade no perfil de formação dos entrevistados na graduação pode ser relacionada com as representações similares quanto às perguntas envolvendo a formação acadêmica e a atividade profissional.

Quase todos os entrevistados relataram ter complementado a formação acadêmica cursando algum tipo de pós-graduação, sendo mais freqüente a "latu sensu" (Tabela I). A área de saúde pública predomina nos cursos de especialização realizados. Isso demonstra um certo 
direcionamento da formação para a área em que os profissionais já atuam. A maior parte dessas especializações foi concluída no final dos anos noventa. Notou-se também, certa freqüência de especialização na área de homeopatia.

TABELA I - Títulos obtidos após a graduação dos entrevistados

\begin{tabular}{lll}
\hline Título & Profissionais $\left(\mathrm{n}^{\circ}\right)$ & Áreas de conhecimento \\
\hline Especialista & 10 & Saúde Pública (5); \\
& & Homeopatia (3); \\
& & Farmácia (2); \\
& Microbiologia (1); \\
& & Acupuntura (1) e \\
& & Nutrição (1) \\
Mestre & 4 & Bioquímica (2); \\
& & Farmácia (1) e \\
& & Saúde Pública (1) \\
Doutor & 2 & Bioquímica (1) e \\
& & Farmácia (1) \\
\hline
\end{tabular}

Quanto aos cursos de Pós-Graduação senso estrito, nos níveis de mestrado e doutorado, as áreas ligadas à saúde pública foram menos freqüentes, com apenas uma ocorrência no mestrado e ausente nos dois casos de farmacêuticos portadores do título de Doutor. Não sabemos a que atribuir este quadro, visto que as informações obtidas não nos permitem fazer associações e dado que o número de profissionais nestes níveis de pós-graduação é reduzido.

Chama atenção o fato de a maioria das especializações ter sido cursada em instituições privadas de ensino, sugerindo falta de oferta deste tipo de curso por parte das instituições públicas. Se atentarmos ao fato que a área predominante destas especializações foi principalmente saúde pública, parece-nos plausível afirmar que esta deveria ser uma das prioridades das Instituições formadoras. Associase a isto o fato do crescimento do emprego formal na farmácia (institucional e privada). Apenas nos casos de mestrado e doutorado, nota-se a participação freqüente da universidade pública, mesmo assim em áreas correlatas.

\section{Análise das entrevistas com os farmacêuticos}

Foram entrevistados treze profissionais, que atuavam em treze unidades de saúde da rede municipal. Alguns deles prestavam atendimento em mais de uma unidade em períodos distintos.

Optou-se por fazer a seleção de alguns trechos das entrevistas que se julgou mais representativos do discurso sobre a Assistência Farmacêutica, tecendo algumas considerações iniciais de seu significado para os objetivos da pesquisa. Também, é importante esclarecer que não é nosso objetivo fazer, a priori, juízos de valor sobre as concepções reveladas pelos entrevistados, mas procurar entendê-las como representações derivadas do contexto real da Assistência Farmacêutica, conforme a visão de seus executores principais.

$\mathrm{Na}$ Tabela II, agrupamos os temas mais recorrentes a partir das respostas obtidas sobre as concepções de assistência farmacêutica, seguindo o roteiro de entrevista.

TABELA II - Principais temas surgidos nas respostas sobre a questão assistência farmacêutica

\begin{tabular}{lc}
\hline Tema & Freqüência \\
\hline Centrado no medicamento & $11 / 13$ \\
Ciclo curto & $8 / 13$ \\
Ciclo longo & $5 / 13$ \\
Centrado no farmacêutico & $2 / 13$ \\
Multiprofissional & $2 / 13$ \\
Clínica & $2 / 13$ \\
\hline
\end{tabular}

De modo geral, as concepções sobre a Assistência Farmacêutica refletem as representações dos profissionais farmacêuticos sobre o seu próprio processo de trabalho rotineiro na unidade de saúde. Nesta visão, que denominaremos de ciclo mais curto da assistência farmacêutica, o medicamento se destaca como o mais evidente objeto de trabalho farmacêutico na unidade de saúde, fortemente marcado pela gestão burocrática, ou seja, garantir a disponibilidade do medicamento ao usuário. A seguir apresentamos alguns trechos de entrevistas:

"Num sentido mais global, né, do trabalho do farmacêutico. Consiste assim, eu acho que é desde v. tá garantindo o medicamento na prateleira, prá ter ele no momento que v. vai entregar ao paciente, tá controlando esse estoque, garantindo o estoque (...) e também a assistência no que se diz respeito no momento da entrega desse medicamento ao paciente." (farmacêutico n. 01).

"A assistência farmacêutica que v. tá dizendo em termos de medicamento, de poder entregar esse medicamento, né. A pergunta anterior. Bom, a gente aqui, é, essa assistência, ela vem, né, da, do Estado, muitas vezes alguns medicamentos, outros vêm da Prefeitura, né, geralmente eles mantêm-se, tem aqueles que são padronizados dentro de programas, né." (farmacêutico n. 07).

Ainda que haja uma clareza desses profissionais quanto à existência de dois processos diferentes na Assistência Farmacêutica, a orientação das atividades é vinculada ao controle de estoque, ancorada na justificativa da 
garantia do acesso ao medicamento, o qual norteia todas as atividades no interior da farmácia.

De nosso ponto de vista, percebemos uma clara influência do referencial oriundo da Carta de Brasília (anônimo, 1988) nesta concepção. Entretanto, conforme analisamos mais detidamente os depoimentos, podemos verificar alguns desdobramentos. Primeiro, parte dos profissionais, cinco deles precisamente, recorre ao que chamaremos de concepção de ciclo mais longo da assistência farmacêutica, a qual envolveria todos os aspectos referentes à política de medicamentos e à atividade farmacêutica, englobando desde a pesquisa, obtenção de matéria-prima, produção e controle de qualidade, até chegar à dispensação do medicamento, eventualmente com atividades de farmacovigilância. Mas, mesmo nessa concepção, percebe-se já certo direcionamento para as atividades mais específicas do trabalho na unidade de saúde:

"E na rede pública, seria conforme eu disse uma aquisição, como não existe a produção aqui em Ribeirão da medicação, a aquisição, o processo de compra, o controle de estoque, os pedidos que a gente faz a nível central, remanejamento de medicação e terminando na dispensação, no controle de validade" (farmacêutico n.08).

Dois entrevistados ancoraram a sua concepção na atividade clínica do farmacêutico na unidade:

"Ou seja, é... você atender o paciente em consultório farmacêutico, onde você disponibiliza a ele é... não só a medicação, como a forma de tomar, efeitos colaterais e principalmente a adesão ao tratamento" (farmacêutico n. 12). Considerado o que deveria ser feito, e não o que realmente a acontece.

Raramente, a assistência farmacêutica foi vista como atividade multiprofissional, o que, de certa forma, confirma a apropriação do termo pela categoria farmacêutica como atividade específica:

"Não é algo só do farmacêutico, isso também é claro, não é só do farmacêutico. Nós somos parte importantíssima aí, em todo o processo, mas não é só do farmacêutico" (farmacêutico n.06);

No caso da Atenção Farmacêutica, a maior parte dos entrevistados refere-se ao termo como um trabalho mais voltado ao paciente, um envolvimento mais específico do farmacêutico com a farmacoterapia. Neste sentido, existem dois desdobramentos principais: pertinência e coincidência. Na Tabela III estão sistematizadas as principais respostas obtidas.

No primeiro desdobramento, a Atenção é definida como uma atividade pertencente à Assistência Farmacêutica. Deste modo, é vista como uma Assistência Farmacêutica mais completa, que ultrapassa a mera gestão de
TABELA III - Principais respostas obtidas na questão atenção farmacêutica

\begin{tabular}{lc}
\hline Resposta & Freqüência \\
\hline Envolvimento maior com o paciente & $10 / 13$ \\
Está dentro da assistência (pertinência) & $4 / 10$ \\
Igual à assistência (coincidência) & $3 / 10$ \\
Clínica & $1 / 13$ \\
Direcionada ao medicamento & $1 / 13$ \\
Acompanhamento farmacoterapêutico & $1 / 13$ \\
Não sabe & $1 / 13$ \\
\hline
\end{tabular}

estoques, um trabalho individualizado junto ao paciente:

"Atenção foi um termo criado a partir assim, seria uma Assistência Farmacêutica, que eu entendo, uma Assistência Farmacêutica ampliada" (farmacêutico n. 03);

No outro desdobramento, Atenção e Assistência correspondem à mesma atividade, não se estabelecendo diferença entre elas:

"Prá mim é a mesma coisa, eles quiseram mudar de assistência prá atenção.... eu entendo que é a mesma coisa. Eu lembro que na época teve bastante discussão em relação a isso, que atenção seria um termo melhor prá função, tal, do que assistência. Ah, mas não existe isso..." (farmacêutico n. 11).

A definição da atividade como um trabalho clínico também foi ocasionalmente referida, juntamente com o termo acompanhamento farmacoterapêutico:

“...Um conhecimento mais clínico da situação da doença e do paciente prá uma orientação. Essa orientação seria um acompanhamento farmacoterapêutico, né..." (farmacêutico n. 13)

Apenas um dos entrevistados afirmou desconhecer o termo Atenção, embora na sua concepção de Assistência Farmacêutica, esteja incluído o trabalho clínico do farmacêutico.

O processo centrado na gestão burocrática aparece de forma mais evidente, quando os profissionais procuraram detalhar os procedimentos da Assistência Farmacêutica, em que, na maior parte do tempo, se referem àquelas tecnologias envolvidas nas atividades de gestão do medicamento, embora também se refiram quase com a mesma freqüência às atividades relacionadas à garantia do uso racional. Na Tabela IV, estão descritos alguns termos mais citados.

Outros termos referidos apenas uma vez foram: atender a demanda, acesso ao medicamento, parte burocrática, licitação e padronização.

Há percepção bastante diversificada do que poderia ser usado como parâmetro de qualidade da Assistência 
TABELA IV - Principais respostas obtidas na questão sobre procedimentos para a realização da assistência farmacêutica

\begin{tabular}{lc}
\hline Resposta & Freqüência \\
\hline Controle de estoque & $7 / 13$ \\
Orientação & $4 / 13$ \\
Entregar a medicação & $4 / 13$ \\
Controle do paciente & $3 / 13$ \\
Distribuição & $3 / 13$ \\
Controle de validade & $2 / 13$ \\
Compra & $2 / 13$ \\
Atenção farmacêutica & $2 / 13$ \\
Farmacovigilância & $2 / 13$ \\
\hline
\end{tabular}

Farmacêutica. Há rotina estabelecida para os aspectos de controle de estoque, tanto da farmácia quanto do paciente. Neste aspecto, é importante frisar que há certo equilíbrio entre os parâmetros relacionados à gestão e aos relacionados ao usuário, sendo que é positivo, ao nosso ver, que a maioria dos entrevistados já percebe o usuário como principal parâmetro de avaliação do serviço. Na Tabela V, procuramos resumir os termos mais encontrados.

TABELA V - Principais respostas obtidas na questão sobre a qualidade da assistência farmacêutica

\begin{tabular}{lc}
\hline Resposta & Freqüência \\
\hline Avaliar a adesão & $4 / 13$ \\
Conversar/perguntar ao paciente & $3 / 13$ \\
Controle de perdas e faltas & $3 / 13$ \\
Controle de estoque & $2 / 13$ \\
Avaliar a orientação & $2 / 13$ \\
Controle do paciente & $2 / 13$ \\
Resultado do tratamento & $2 / 13$ \\
Parte burocrática & $1 / 13$ \\
Normas sérias & $1 / 13$ \\
Contratar farmacêuticos & $1 / 13$ \\
Conversar com equipes de pré e & $1 / 13$ \\
pós-consulta & \\
Indices epidemiológicos & $1 / 13$ \\
Atenção farmacêutica & $1 / 13$ \\
Qualidade no atendimento & $1 / 13$ \\
Verificar se sobrou/faltou medicamento & $1 / 13$ \\
Atender a demanda & $1 / 13$ \\
\hline
\end{tabular}

No caso, a formação acadêmica foi entendida como tendo dado apenas uma base técnica e científica, destacando-se a pouca prática e/ou contato com o paciente, ou, ainda, como não tendo oferecido preparação nenhuma para o exercício da Assistência Farmacêutica.
Os dados obtidos são condizentes com o fato de a formação acadêmica dos entrevistados pouco ou quase nada tê-los preparado para a atividade junto ao usuário do medicamento. Chama a atenção que a maioria deles tenha se referido à graduação como tendo fornecido boa base técnica e científica, mesmo sem a prática ou contato com o paciente. Parece-nos haver neste raciocínio pelo menos duas contradições.

Primeiro, o fato de considerar a formação técnica e científica suficiente leva a questionar logo em seguida dos objetivos da formação, ou seja, técnica e científica para quê? Para o medicamento? Para a indústria ou análises clínicas? Técnica por si mesma? Segundo, se a formação foi técnica e científica e não preparou para a assistência farmacêutica, então há a necessidade de questionar-se em qual área os entrevistados localizam as atividades que executam no dia a dia na unidade. Neste sentido, parecenos pertinente deduzir um certo academicismo no pensamento dos entrevistados, entendendo-se este como valorização apenas do conhecimento produzido na academia como técnico e científico.

Há certo consenso de que o complemento da formação acadêmica se deu na prática diária e, em alguns casos, nos cursos de especialização e aperfeiçoamento. Quando se observam os cursos referidos pelos entrevistados, mesmo na área de saúde pública, não parece que eles tenham complementado adequadamente a formação para a assistência farmacêutica:

"Mas saúde pública é muito restrito e às vezes quando tem, também, não é exatamente aquilo que a gente precisa no nosso serviço" (farmacêutico n.10).

Neste caso, é preciso questionar qual modelo de formação seria o mais adequado para sistematizar essa prática, ou, ainda, se tal prática pode ser contemplada no atual modelo de graduação do farmacêutico, visto que não parece ter havido grandes alterações no perfil do profissional formado nos últimos anos, com os problemas apontados, principalmente no que se refere à dispensação, sendo estes de longa data conhecidos e debatidos na categoria. Nesta linha de raciocínio, não parece ser apenas questão de conteúdos a serem ensinados.

A atualização profissional se deu quase sempre de forma passiva. Freqüentemente, são citados cursos que a própria secretaria oferece ou periódicos de instituições profissionais entregues em domicílio. Também são citados com certa freqüência os congressos, quase sempre em área diversas da assistência farmacêutica.

A realização de eventos e a obtenção de fontes de atualização mais específicas sobre o trabalho assistencial farmacêutico constituem, ainda, necessidade dos profissionais entrevistados, assim como maior incentivo para a 
participação, dada a pouca disponibilidade de tempo e recursos financeiros relatados por eles.

A interação do farmacêutico com a equipe de saúde foi citada como ocasional e vinculada à ocorrência de problemas operacionais da gestão dos estoques ou de dúvidas quanto à prescrição (quantidade do medicamento, letra do médico, dosagem e outras). Pelos depoimentos obtidos, ficou evidente que qualquer trabalho mais sistemático de equipe de saúde tendo como insumo o medicamento, pelo menos neste caso, fica limitado ao aspecto pessoal. Neste sentido, cai por terra aquela visão de assistência farmacêutica multiprofissional, quando o trabalho na unidade não corresponde a esta realidade. Em nosso estudo, constatamos segmentação do trabalho com o medicamento, centralidade na gestão normatizada e atuação técnica do farmacêutico no sentido do cumprimento dessas normas:

"Infelizmente, uma coisa que até a semana passada, nós fizemos uma reunião aqui com a equipe da farmácia e comentamos isso, que seria muito importante. Às vezes, a gente faz uma alteração de um medicamento, então a gente tem de sair médico em médico conversando" (farmacêutico n.08).

Os médicos foram descritos com comportamentos variáveis quanto ao trabalho farmacêutico, mas freqüentemente parecem estar muitos distantes de toda essa realidade. O que chama a atenção, dada a diretriz da integralidade do sistema de saúde, é o fato de que cada profissional da unidade parece exercer a sua atividade isoladamente, recorrendo aos outros apenas nos casos em que a gestão interna esteja ameaçada, não importando muito o conhecimento técnico sobre os medicamentos:

"Tinha um médico (...) que mandava fracionar a nifedipina, cortar a drágea. É uma drágea de liberação lenta, não pode cortar a drágea. Fui lá, expliquei prá ele o que é o drageamento, ele entendeu, nunca mais prescreveu. Tem outro que eu já falei e ele continua prescrevendo" (farmacêutico 05).

Nos trabalhos junto a programas específicos parece haver maior interação. Não podemos esquecer, entretanto, dos aspectos subjetivos que permeiam todo e qualquer relacionamento em grupo. Mesmo assim, verificamos algumas soluções interessantes:

"A gente faz um trabalho também, é, agora a gente não tá tendo mais, mas nós já tivemos com o programa da tuberculose e hanseníase, eles iam fazer reuniões de equipe e a farmácia tava junto" (farmacêutico n.06).

Quanto às dificuldades para o efetivo exercício da Assistência Farmacêutica, o problema de falta de recursos humanos qualificados está presente na totalidade das respostas obtidas. Neste quadro fica evidenciada a contraposição entre as atividades da gestão de estoques para atendimento de demandas e a atividade de orientação ao paciente:

"Porque o volume é grande de trabalho. Não só prá $\mathrm{v}$. atender o pessoal, mas v. tem que conferir estoque, $\mathrm{v}$. tem que controlar o teu estoque, v. tem que fazer boletim, v. tem que fazer balanço, tem que fazer livro de psicotrópico. Então, uma série de exigências burocráticas de controle de uma farmácia" (farmacêutico n. 03).

A falta de medicamentos para o atendimento das demandas também foi bastante citada. Neste caso, particularmente, verifica-se a dificuldade para a realização das atividades de orientação em situação de extremo conflito que se estabelece na unidade de saúde dada à localização da farmácia no elo final do processo de atendimento, onde vão desaguar quase todas as mazelas do sistema de saúde:

"A farmácia é o último lugar em que ele passa praticamente, né. Então, ele já tá muito cansado, duas horas que ele tá aqui esperando consulta, espera triagem. Então, ele chega na farmácia, último lugar já querendo mais é pegar o remédio e ir embora" (farmacêutico n. 11).

Percebemos, neste caso, contradição com o discurso oficial de que o farmacêutico tem um papel relevante a cumprir no sistema de saúde (OMS, 1988), devido ao seu perfil de conhecimento técnico na área de medicamentos. Essa realidade ainda não se faz presente na representação que o profissional faz de seu trabalho e do reconhecimento obtido perante os gestores e a sociedade.

A maior parte dos entrevistados (9/13) referiu-se ao objeto de trabalho como sendo o paciente, embora alguns (5/13) também incluam o processo de atendimento. Vemos aí a tomada de consciência do farmacêutico, no sentido de posicionar-se como profissional da saúde, e na vivência de suas contradições redefinir o trabalho com o medicamento, dando nova amplitude a ele. Neste sentido, não está descartado que este discurso represente não somente mudança operacional na atividade farmacêutica, mas pode ser também mudança importante de paradigma do modo de atuação dos profissionais entrevistados, que incorpora a dimensão clínica ao trabalho.

Sobre este aspecto, Franco et al., (1999) defendem que a relação do trabalhador de saúde com o usuário do serviço sempre tem dimensão clínica, definida pelo autor como "um encontro de necessidades e processos de intervenção tecnologicamente orientados, os quais visam operar sobre o campo das necessidades que se fazem presentes nesse encontro, na busca de fins implicados com a manutenção elou recuperação de um certo modo de viver a vida". O espaço tecnológico das relações onde se dá esse encontro é um espaço clinicamente evidente. 
Apesar de não ter emergido das entrevistas projeto político consensual para a categoria, há, contudo, percepção das necessidades e algumas idéias no sentido de melhorar as condições de trabalho. A maior parte das sugestões, como prontamente se apresentam nas entrevistas, repetem o discurso da necessidade de melhorar as condições operacionais e de reconhecimento profissional, assim como de convênios com universidades e mudanças na formação do profissional:

"Olha. É. A realidade que a gente vive no município hoje e as perspectivas futuras é de que não haverá com facilidade esses investimentos que a gente julga necessários. Então, uma coisa que a gente precisa, com uma certa urgência até, é tá discutindo assim alternativas prá gente vencer esses obstáculos e uma das alternativas que nós vemos hoje em dia são convênios com universidades" (farmacêutico n. 04).

"Eu acho que os currículos das universidades têm que ser reavaliados nesse sentido, né, de tá formando um profissional farmacêutico mesmo, voltado prá assistência farmacêutica" (farmacêutico n. 13).

O reconhecimento de que o modelo de atendimento centrado no medicamento não consegue atender às necessidades do usuário, talvez, seja a mudança mais importante constatada em nosso estudo. Nesse fato situamos o ponto de partida de outros processos que poderão tomar forma em relação à prática farmacêutica na rede básica de saúde. Acreditamos, contudo, que um pouco de criatividade pode ser determinante para a velocidade dessas mudanças.

Uma idéia interessante que podemos comentar está presente num trabalho de Cecílio (1997), no qual o autor propõe discussão sobre a idéia mais comum de modelo tecno-assistencial vigente no SUS, baseado na imagem da pirâmide, com a atenção primária na base e os serviços hospitalares de maior complexidade no topo. Em sua proposta, chamada de círculo, a missão da unidade básica seria a de se responsabilizar, dentro de sua área de cobertura, pela vigilância à saúde e pelo estabelecimento de vínculos com as equipes onde fosse necessário atendimento contínuo e não mais por toda demanda que bate à sua porta, reproduzindo os serviços de urgência. Dentro desta lógica, "a referência passa a ser as pessoas e suas necessidades e não qualquer tipo de modelo assistencial". O estabelecimento de protocolos adequados baseados no acolhimento e nas necessidades dos usuários seria a referência de toda a tecnologia, considerando-se que "qualquer serviço de saúde é espaço de alta densidade tecnológica, que deve ser colocada a serviço da vida dos cidadãos".

Ao nosso ver, a definição de tecnologias adequadas para a promoção do uso racional dos medicamentos no sistema de saúde passa pela análise do estágio atual de organização da Assistência Farmacêutica no Brasil, no qual temos esta como parte indissociável do modelo assistencial existente. Nesta linha de abordagem, algumas tentativas mais recentes colocam o assunto de forma mais ampla:

"Assistência Farmacêutica constitui, portanto, um componente da política de medicamentos, essencial no sistema de saúde, sendo prioritária e imperativa a sua definição, organização e estruturação nos diversos nivveis de atenção à saúde, com ênfase no setor público, no marco da "transformação do novo modelo assistencial de vigilância à saúde" (Carlos, 1997).

Dentre seus objetivos estão: assegurar a acessibilidade de medicamentos e farmacoterapia de qualidade à população, com ênfase nos grupos de risco; garantir o uso racional de medicamentos e de insumos farmacêuticos; oferecer serviços farmacêuticos e cuidados ao paciente e à comunidade, complementando a atuação de outros serviços de atenção à saúde e contribuir de maneira eficaz e efetiva para transformar o investimento com medicamentos em incremento de saúde e de qualidade de vida.

Deste ponto de vista a Assistência Farmacêutica inclui não somente as atividades ligadas à compra e distribuição de medicamentos, mas todas aquelas direcionadas ao uso racional e melhoria do sistema logístico, com uso de mecanismos de mercado e de controle comunitário.

Avanço no plano estatal, pelo menos no aspecto legislativo, pode-se observar na atual Política Nacional de Medicamentos (PNM)(Brasil, 2001), em que se busca melhor detalhamento de funções e responsabilidades quanto à Assistência Farmacêutica. Neste sentido, incluem-se as atividades de seleção, programação, aquisição, armazenamento e distribuição, controle de qualidade e utilização com base em critérios epidemiológicos.

Busca-se, desse modo, garantir o uso racional do medicamento, o qual inclui série de estratégias que vão melhorar a prescrição e a dispensação de medicamentos, dentre as quais têm-se: promover estudos sobre utilização de medicamentos e discutir seus resultados com os profissionais e promover programas de informação ao cidadão e ao doente (Jorcheere, 1997).

Neste marco teórico, podemos distinguir duas áreas imbricadas, porém distintas. Uma está relacionada à tecnologia de gestão do medicamento, de forma a garantir o abastecimento e o acesso. A outra está relacionada à tecnologia do uso do medicamento, na qual estão envolvidas diferentes classes profissionais suas atitudes e usuários, cujo conjunto visa ao uso correto e eficaz dos medicamentos. Estas áreas possuem aspectos diferentes, prin- 
cipalmente aqueles relacionados às atividades e perfil profissional para executá-las.

Do nosso ponto de vista, apesar do envolvimento de vários atores neste teatro de operações, na prática a responsabilidade de direção deste processo cabe ao profissional farmacêutico, pelo seu histórico vínculo indissociável com o medicamento.

A tecnologia de gestão, após sua implantação, pode ser caracterizada como tendo forte participação de atividades previsíveis e repetitivas, necessárias ao cumprimento dos aspectos legais e as diretrizes das políticas de saúde, ou seja, são atividades vinculadas a normas e procedimentos pré-estabelecidos, reduzindo o grau de liberdade e criatividade dos atores.

Esta tecnologia foi implantada, nos diferentes níveis, a partir da década de 1990, em Ribeirão Preto, cujos progressos e aperfeiçoamentos foram relatados por Mestriner (2003).

Por outro lado, a tecnologia do uso dos medicamentos tem como forte componente, além do conhecimento eclético, as relações interpessoais e a habilidade de comunicação em linguagem adequada ao interlocutor. A execução desta atividade depende da anterior, uma vez que a disponibilidade do instrumento de trabalho, medicamento, é fruto da gestão.

Como esta atividade envolve relações interpessoais e habilidade de comunicação, tem dificultado o estabelecimento de procedimentos que o profissional farmacêutico deva realizar para executá-la de maneira adequada. Além disso, a realização parcial ou integral dos procedimentos, de maneira geral, é condicionada às condições do local de trabalho e do empregador.

De modo geral, o que constatamos neste estudo representa o atual estágio da Assistência Farmacêutica no Brasil, ou seja, trata-se de uma área ainda incipiente. A falta de um modelo que norteie as práticas da Assistência Farmacêutica nos sistemas locais é um dos fatores que tem dificultado sua evolução. Este modelo deve ser construído de forma sistêmica e suas tecnologias devem ser adequadas às necessidades do sistema e dos usuários.

\section{AGRADECIMENTOS}

À farmacêutica Darlene C. Mestriner, chefe da Divisão de Farmácia e Apoio Diagnóstico da Secretaria da Saúde de Ribeirão Preto e ao Dr. Luiz Carlos Raya (em memória), então Secretário Municipal de Saúde de Ribeirão Preto, pelo apoio e autorização para a realização do trabalho.

A todos os farmacêuticos que participaram do trabalho.

\section{ABSTRACT}

Conceptions of the pharmaceutical professional about the pharmaceutical assistance in basic health care units: difficulties and elements for change

In the present study we evaluated the Pharmaceutical Assistance in pharmacies of Basic Health Care Units in Ribeirão Preto, State of São Paulo, Brazil. Considering the technological evaluation reference in health and its interfaces, pharmaceutical professionals were interviewed in a way to find out their conceptions about pharmaceutical assistance. The results showed a work based on the bureaucratic management of medicines specially the control of medicine supplies. Some emergent elements were thought to contribute to change this system: voluntarism, professional valorization, integration of the health team, perception of the patient as object of the work and complementary professional formation.

UNITERMS: Phamaceutical assistance. Technology. Pharmaceutical care.

\section{REFERÊNCIAS BIBLIOGRÁFICAS}

CARTA de Brasília. I ENCONTRO NACIONAL DE ASSISTÊNCIA FARMACÊUTICA E POLÍTICA DE MEDICAMENTOS, 1., Brasília, 1988. Relatório Final. Brasília: Ministério da Saúde, 1988.

BRASIL. Ministério da Saúde, Secretaria de Políticas de Saúde, Departamento de Atenção Básica. Política Nacional de Medicamentos. Brasília, 2001.

CAMPOS, G. S. Modelos assistenciais e unidades básicas de saúde: para debate. In: Planejamento sem normas. São Paulo: Hucitec, 1979. p. 53.

CAMPOS, G.W.S. Reforma da reforma: repensando a saúde. São Paulo: Hucitec, 1992.

CARLOS, I.C.C. O sistema integral de assistência farmacêutica no Ceará. In: BONFIM, J.R.A., MERCUCCI, V.L. (Eds.) A construção da política de medicamentos. São Paulo: Hucitec e Sobravime, 1997. p. 107.

CARVALHO, M.C. Modelos assistenciais de unidades básicas e o conceito de intregalidade. In: BODSTEIN, R. (Org.). Serviços locais de saúde: construção de atores e políticas. Rio de Janeiro: Relume, 1993. p. 119-130. 
CECÍLIO, L.C.O. Modelos tecno-assistenciais em saúde: da pirâmide ao círculo, uma possibilidade a ser explorada. Cadernos de Saúde Pública, v. 13, n. 3, 1997. Disponível em: $<$ http://www.scielosp..../fbtext?got=last\&pid=S0102$311 \mathrm{X} 1997000300022 \& \operatorname{lng}=\mathrm{pt} \& \mathrm{nrm}=\mathrm{is}>$. Acesso em: 22 jul. 2000.

DURKHEIN, E. As regras do método sociológico. Pensadores. São Paulo: Ed. Abril, 1978. p. 71-156. Apud: MINAYO, M.C.S. O desafio do conhecimento: pesquisa qualitativa em saúde. São Paulo: Hucitec/ Abrasco, 2000. p. 160.

FRANCO, T.B.; BUENO, W.S.; MERHY, E.E. O acolhimento e os processos de trabalho em saúde: o caso de Betim, Minas Gerais, Brasil. Cadernos de Saúde Pública, v. 12, n. 2, p. 345-53, 1999.

GONÇALVES, R.B.M. Tecnologia e organização social das práticas de saúde. São Paulo: Hucitec/Abrasco, 1994.

ITURRI, J. Ciberespaço e negociações de sentido: aspectos sociais da implementação de redes digitais de comunicação em instituições acadêmicas de saúde pública. Cadernos de Saúde Pública, v. 14, n. 4, 1998. Disponível em: $<$ http://www.scielosp..../fbtext?got=last\&pid=S0102311X1998000400013\&lng-pt\&nrm=is $>$ Acesso em: 22 jul. 2000.
JONCHEERE, K. A necessidade e os elementos de uma política nacional de medicamentos. In: BONFIM, J.R.A., MERCUCCI, V.L. (Eds.) A construção da política de medicamentos. São Paulo: Hucitec/Sobravime, 1997. p. 49.

MESTRINER, D.C.P. O farmacêutico no serviço público de saúde: a experiência do município de Ribeirão Preto-SP. Ribeirão Preto, 2003, 134 p. [Dissertação de Mestrado, Faculdade de Medicina de Ribeirão Preto, Universidade de São Paulo].

MINAYO, M.C.S. O desafio do conhecimento: pesquisa qualitativa em saúde. São Paulo: Hucitec/Abrasco, 2000.

NOVAES, H.M.D. Avaliação de programas, serviços e tecnologias em saúde. Rev. Saúde Públ., v. 34, n. 5, p. 547-59, 2000.

ORGANIZACION MUNDIAL DE LA SALUD. El papel del farmacéutico em el sistema de atención de salud. Nueva Delhi, OMS, 1988. Informe de um grupo de consulta de la OMS.

Recebido para publicação em 22 defevereiro de 2005. Aceito para publicação em 29 de julho de 2005. 